\title{
O TEMPO DE ELABORAÇÃO DE UM "EU PROFESSOR"
}

\author{
THE ELABORATION TIME OF THE 'I, A TEACHER"
}

\section{EL TIEMPO DE ELABORACIÓN DE UN "YO PROFESOR"}

Claudine Blanchard-Laville ${ }^{1}$, Arnaud Dubois ${ }^{2}$

\section{RESUMO}

A partir de pesquisas realizadas no âmbito da clínica de orientação psicanalítica em ciências da educação na França, queremos mostrar que a construção da identidade de um professor se estende ao longo de vários anos. É um processo gradual marcado por um passo semelhante a uma crise da adolescência profissional, durante o qual a relação com o saber profissional tem suas próprias características. Nós mostraremos, então, quais são as formas de acompanhamento que nos parecem mais adequadas, para levar em consideração os resultados dessas pesquisas sobre os primeiros anos de exercício da profissão docente.

PALAVRAS-CHAVE: Formação de professores. Psicanálise. Prática docente.

\begin{abstract}
Departing from researches that took place in the scope of clinical psychoanalysis in application on the sciences of education in France, we wish to show that the construction of teacher's identity is long-term oriented process. A process somewhat similar to a crisis in the professional adolescence, during which the relation with knowledge has its own characteristics. Thus, we will try to show the different forms of adequate accompaniments to seriously consider the results of these researches about the early years of the exercise of docentship.
\end{abstract}

KEY WORDS: Training teachers. Psychoanalysis. Teaching practice.

\section{RESUMEN}

A partir de investigaciones realizadas en el ámbito de la clínica de orientación psicoanalítica en ciencias de la educación en Francia, queremos mostrar que la construcción de la identidad de un profesor se extiende a lo largo de varios años. Es un proceso gradual, marcado por un paso similar a una crisis de la adolescencia profesional, durante el cual la relación con el saber profesional tiene sus propias características. A continuación, mostraremos cuáles son las formas de seguimiento que nos parecen las más adecuadas para tener en cuenta los resultados de esas investigaciones sobre los primeros años de ejercicio de la profesión docente.

PALABRAS-CLAVE: Formación de profesores. Psicoanálisis. Práctica docente.

\footnotetext{
${ }^{1}$ Professor Emérito de Ciências da Educação. Universidade de Paris - Nanterre - Paris, França. Professor Associado no Laboratório EDA da Universidade de Paris - Descartes - Paris, França.

E-mail: claudine.blanchard-laville@wanadoo.fr

2 Mestre de Conferências em Ciências da Educação (Sétima Seção CNU). Universidade de Cergy-Pontoise -

Paris, França. E-mail: arnaud.dubois@u-cergy.fr

Submetido em: 11/09/2018 - Aceito em: 22/11/2018
}

(C) ETD- Educação Temática Digital Campinas, SP $\quad$ v.21 n.2 $\quad$ p.382-394 abr./jun. 2019 


\section{INTRODUÇÃO}

A partir de pesquisas realizadas no âmbito da clínica de orientação psicanalítica em ciências da educação na França (BLANCHARD-LAVILLE, 2007), queremos mostrar que a construção da identidade de um professor se estende ao longo dos primeiros anos de exercício da profissão, e indicar em seguida quais são as formas de acompanhamento que nos parecem as mais adequadas para levar em consideração os resultados dessas pesquisas no que diz respeito aos novos docentes.

De acordo com a nossa orientação, consideramos, em primeiro lugar, os processos psíquicos envolvidos na construção de uma posição psíquica docente. Esses processos são infinitamente complexos e exigem muito tempo para um "Eu docente" ser construído, atravessando uma crise que chamamos de adolescência profissional, a qual permite moverse gradualmente para uma posição de adulto profissional.

O que normalmente se chama por "entrada na profissão" na literatura francesa para professores iniciantes é um período que se estende de 1 a 5 anos após o cargo ter sido assumido. Nossas pesquisas na perspectiva de uma orientação psicanalítica indicam que se exige um tempo mais longo para passar de uma posição de estudante a uma posição de professor no nível psíquico. É impossível determinar a duração exata desse período porque ele varia com a subjetividade e a história psíquica de cada um. Prevemos uma evolução que se estende por cerca de uma década desde o início da carreira. Para nós, o crescimento profissional psíquico não é um processo linear e não corresponde a uma sucessão de etapas de desenvolvimento. Em vez disso, ela é submetida a fases de regressão, bem como movimentos progressivos, sem que essa sequência seja previsível ou mesmo sistemática. Ela passa por uma fase de crise cujo desfecho é incerto.

\section{A CRISE DA ADOLESCÊNCIA PROFISSIONAL}

Baseamo-nos em uma pesquisa longitudinal realizada a partir de entrevistas clínicas, a qual resultou na publicação do trabalho na formação de professores no ano 2000, assim como em um relatório apresentado aos patrocinadores dessa pesquisa. Lendo os discursos dos professores estagiários de primeiro e segundo ano do Institut Universitaire de Formation des Maîtres (IUFM) - essa pesquisa ocorreu enquanto ainda existiam IUFMs na França, os quais foram substituídos pelas Écoles Supérieures du Professorat et de L'Éducation em 2013 constatamos que estamos nos confrontando, em primeiro lugar, com a diversidade de palavras e opiniões, isto é, o aspecto singular do discurso em cada entrevista. O que se impõe, gradualmente, é a uniformidade de uma objeção persistente sobre a formação recebida. Seja qual forem os percursos e lugares de formação em que as entrevistas analisadas foram coletadas, todos os estudantes e estagiários parecem falar com uma só voz "para reclamar que algo está errado". Constatamos, com Benjamin Jacobi (1998), que o protesto não é destinado a comunicar uma causalidade, "nem para aquele que a estabelece nem para aquele

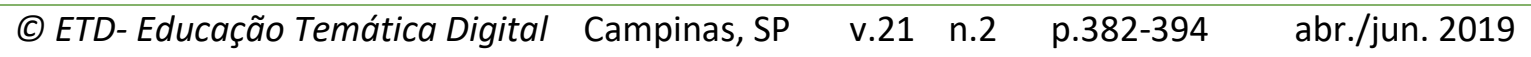


que é testemunha e [...] destinatário" (JACOBI, 1998, s/p.), porque "o que o sujeito exprime no reclame da objeção deve ser entendido ao mesmo tempo com o poder evocativo dos significantes que a compõem" (JACOBI, 1999, s/p.).

Assim, para o clínico, atribuir uma causa para a expressão de uma objeção o faz correr o risco de privar o sujeito de um acesso potencial a seu próprio discurso e aos significados que ele carrega. A procura do motivo, da causa, apresenta um risco de impasse para o trabalho clínico. Reclamar provoca mais reclamações. Portanto, nesta pesquisa, começamos a ouvir as palavras que expressam protestos para trazer certos significados. Um dos pesquisadores da equipe que participaram desse trabalho, Daniel Motteau (2000), observou que

\footnotetext{
os entrevistados têm a sensação que "o encontro formativo" não se realiza realmente. Estudantes e estagiários evocam várias defasagens com suas expectativas - que eles não conseguem explicar concretamente - e os diferentes métodos de formação disponíveis para eles; defasagem entre a formação para o concurso e a formação do trabalho para os estudantes; defasagem entre teoria e prática com mais frequência para os estagiários. (MOTTEAU, 2000, s.p).
}

Esse mal-estar psíquico sentido pelos entrevistados foi interpretado pelos clínicos da equipe de pesquisa, especialmente por Louis-Marie Bossard (2000), em termos de "crise de identidade no plano psíquico". Assim, entendemos o mal-estar expresso como a dificuldade dos professores em formação em viver esse período de crise. Identificamos especialmente em seus discursos movimentos incessantes de oscilação entre satisfação e insatisfação. Essa oscilação reflete a sensação de estar em uma situação instável: nem estar na situação que tinham antes, ou seja, a de um estudante; nem naquela que desejam, a de professor. Os treinados se sentem no meio, "entre dois mundos", como alguns dizem. Essa crise, já identificada por outros pesquisadores sobre a entrada na profissão de docente, pareceu-nos ser iniciada já no primeiro ano da formação, mesmo se os alunos não sabem se eles vão realmente tornar-se professores no próximo ano: "O fato de ter esperança de se tornar um professor inicia uma reformulação de identidade que precede a transição efetiva da posição do aluno para a posição de professor", escreve Louis-Marie Bossard (2000, p. 97).

Esse mal-estar se traduz especialmente na forma como os alunos vivem sua relação com o tempo. Assim, indicamos a dificuldade dos treinados em desistir dos pontos de referência de identificações do passado para se tornar pontos ainda desconhecidos. Notamos que eles se encontram, então, em busca de saberes que lhes garantiriam ir contra o risco de um futuro imprevisível, embora, talvez, pelo contrário, eles devessem renunciar aos poucos e em parte a essas garantias antigas para estar prontos a desafiar os riscos da profissão docente.

De fato, o saber a partir do vivido, especialmente sua formação escolar, pode fornecer apenas modelos relativamente inadequados, os quais podem até não lhes permitir enfrentar

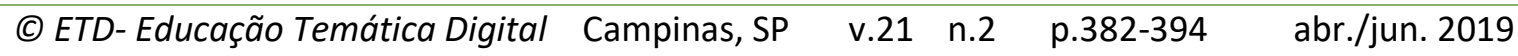


a aventura do desconhecido para o cargo de professor. Os professores iniciantes são exalunos e, como tal, geralmente não observam que, na prática pedagógica de seus professores, se poderia notar gestos ou técnicas profissionais. Por exemplo, eles geralmente têm a lembrança de um professor ou de outro, não por sua capacidade de tomar as decisões mais adequadas para promover a aprendizagem, mas pela impressão que ele poderia deixá-los.

Ao nível psíquico, como sublinha Alexandra Triandafillidis (2010, p. 443), podem se opor duas modalidades da relação com o tempo futuro: uma que invoca o passado e outra que convoca o porvir. A primeira modalidade da relação com o futuro "prenderia no passado o 'saber' do que está porvir, enquanto a outra modalidade envolveria o risco de imaginar um futuro que não se refere a nenhuma experiência do passado". Esse modelo da relação com o tempo futuro nos permite considerar quais são os tipos de perturbação e ajustamento com que estão confrontados os treinandos, e por quais etapas eles deveriam ser obrigados a passar.

Assim, comparamos seu estado de instabilidade profunda ao da adolescência e classificamos essa fase de formação de valência dupla, tanto de maturação, mas também período de alto risco da fase da adolescência profissional. De fato, como na adolescência, a transformação exigida dos pontos de referência traz um papel central à problemática do narcisismo e da identidade. Se esse período é rico em potencialidades, também é definido pela dissociação e pelo negativo.

Em 2004, em sua tese intitulada Da posição de/a estudante à posição de professor/a do ensino médio, a abordagem clínica da passagem (no original, De la situation d'étudiant/e à celle d'enseignant/e du second degré, approche clinique du passage), Louis-Marie Bossard aprofundou essa questão: ele faz um estudo detalhado das pesquisas realizadas desde os anos 1990 sobre o início da profissão, relacionando-as com a formação dos professores. 0 autor mostra que a questão da "passagem" do estado de aluno para o de professor é muito pouco estudado. Sua pesquisa dos resumos das diversas Bienais de Educação, que ocorreram entre 1992 e 2002, permitiu-Ihe mostrar que "a dimensão psíquica dos processos que podem existir nas pessoas que fazem a transição do estado de estudante ao de professor (a) quase nunca foi relatado", e que "os sujeitos que se tornam professores [são geralmente] considerados como objetos que tentaríamos moldar" (BOSSARD, 2000, p. 124). Com base no trabalho de N. Mosconi (1990) e Blanchard-Laville (1995), Louis-Marie Bossard (2000) retoma a ideia de considerar essa passagem do estado de estudante para o de um professor como uma "crise da adolescência".

Mais recentemente, em sua tese, Marc Guignard (2009) aproveitou o conceito de Louis-Marie Bossard para considerar uma "pós-adolescência profissional", porque a mudança vivida pelos professores iniciantes se estende durante os primeiros anos e o final dessa fase não é sistemática: não podemos prever nem como, nem quando termina tal momento. Pode ser que não encontremos nenhum sinal de saída da crise de identidade, e que a posição de

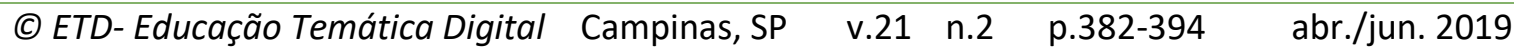


adolescência profissional continua como ele descreveu em seu artigo de 2001 sobre o caso da professora que nomeou Soizic.

Se o tempo de formação deve ser entendido como um tempo da adolescência profissional, os formadores devem acompanhar essa passagem particular. Ora, tal questão da "fase adolescente" no ambiente profissional não tem sido muito trabalhada até agora. Esses adolescentes profissionais, que são professores em formação, levantam a questão de construir um quadro institucional adequado para a realização do trabalho psíquico necessário a esse tipo de integração do estranho em si e para a travessia desse espaço de mutações, que pode afastar a angústia do vazio entre duas gerações. Esse "entre-dois", sublinha Daniel Sibony (1997), implica a identificação e a despersonalização e anima aos formados uma busca exigente de polos de identificação forte o suficiente para atraí-los, de modo a fazê-los se mexer, e não forte o suficiente para fazê-los se fixar.

Assim, nesse caso, os instrutores têm de suportar ser acusados pelos formados de não gerir bem o tempo, de não lhes dar os conhecimentos adequados, de não contar o que sabem, sem "desmoronar-se". Mas como abrir esse tempo instaurador de passagens? Isso pressupõe que os formadores se evadem de sua própria rede de idealidades para não impor aos formados o peso de seu próprio ideal, quase parental, e que eles podem sustentar a prova da transicionalidade, com todo seu cortejo de processos paradoxais. Isso, em particular, exige tolerar o paradoxo, sabendo que os paradoxos não são todos patógenos, mas podem, pelo contrário, uma vez tolerados, contribuir para o enriquecimento dos processos de maturação, como escreve René Roussillon (2013).

\section{3 “O COLAPSO DO CHÃO DA EVIDÊNCIA"}

Por sua parte, Arnaud Dubois (2015), a partir da análise de monografias escritas por professores iniciantes dentro de grupos de análise das práticas profissionais, propõe fazer uma aproximação do "abalo" vivido por professores iniciantes com o que S. Mijolla-Mellor chama, para as crianças, de "colapso do chão da evidência" (1999, p. 20). Para explicar essa aproximação, relembra as propostas de S. Freud sobre teorias sexuais infantis, ponto de partida da conceitualização de Mijolla-Mellor. Freud formulou sua concepção das teorias sexuais infantis em um conjunto de textos, entre 1905 e 1914, entre eles um artigo de 1908 intitulado Sobre as teorias sexuais infantis.

Para Freud, o "primeiro grande problema da vida" das crianças concerne à questão: "De onde as crianças vêm?"; a qual, sem dúvida, significa antes de tudo "De onde veio essa criança perturbadora aí?" (FREUD [1908], 2007, p. 230). Ainda de acordo com o autor, essa "primeira questão-enigma [é], como todas as pesquisas, um produto da necessidade da vida, como se tivesse sido dada a tarefa para o pensamento de prevenir a recorrência de eventos tantos temidos" (ibid.).

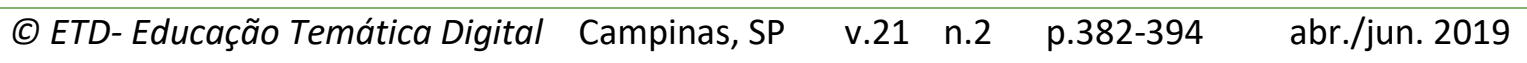


Em suas análises, Arnaud Dubois (2015) propôs ligar essa primeira questão-enigma, identificada por Freud, com as questões colocadas pelos novos professores em formação, podendo ser formulada assim: "De onde veio este [aluno] perturbador aí?". Essa questão é quase idêntica àquela feita pelos novos professores em formação quando se referem ao caso de um aluno "perturbador" em suas salas de aula. Eles então fazem apenas a substituição da palavra "criança", usada por Freud, pela palavra "aluno".

Mijolla-Mellor se baseou nos textos de Piera Aulagnier (1975) para questionar a teoria freudiana do despertar da busca pelo saber. Ela levantou dúvidas quanto à abordagem freudiana em três pontos e sugeriu uma abordagem do conceito de "mito mágico-sexual infantil" que, segundo ela:

\begin{abstract}
Coloca em questão a teoria freudiana [e] se baseia sobre o que ela considera como sendo a origem de todo pensamento, que nasce a partir do colapso do chão da evidência, quando esse colapso pode ser o objeto de um domínio erotizado [...]. Daí a necessidade de vincular as teorias sexuais infantis não só ao surgimento do irmão mais novo, mas a todas as ocorrências em que a criança toma consciência da não evidência do vínculo de amor que a liga aos seus pais por meio dos quais ela constrói sua identidade" (MIJOLLA-MELLOR, 1999, p. 20).
\end{abstract}

Mijolla-Mellor (1999) mostra que o nascimento do outro oferece à criança uma formulação para a pergunta sobre a sua origem, mas também sobre o fim. Assim, "a representação de não ter existido sempre e de não lhe ser assegurado existir sempre, somado a não evidência do vínculo de amor para a criança, cria um equivalente da castração no domínio da identidade" (ibid.). É aí que devemos, segundo ela, "ver o ponto de partida de uma necessidade de causalidade para restaurar o sentido que desabou" (ibid.). Mijolla-Mellor explica as etapas de elaboração desses mitos na criança: quando nada vem superar a angústia ao ponto em que a única solução possível se torna a inibição do pensamento em todas as suas formas, o primeiro ato da démarche da criança consiste primeiramente em passar da desordem à criação de um enigma. Isso poderia se resumir ao saber, ao sentido da "sensação intelectual" que há algo fundamental, vital, que não se sabe, que seria muito excitante de saber, mesmo se isso pode também ser proibido, até mesmo perigoso. Ela acrescenta que "a próxima etapa é aquela que passará da criação do enigma a tentativas de respostas pela criação [...] de mitos mágico-sexuais" (MIJOLLA-MELLOR, 1999, p. 21).

Arnaud Dubois (2015) considera que alguns dos desafios da relação com o saber dos novos professores pode ser melhor analisado se nos referirmos aos conceitos de MijollaMellor sobre mitos mágico-sexuais. Ela considera que "a origem de todo pensamento nasce do colapso do chão da evidência". Para ela, essa "desordem" que se origina no desejo de saber deve ser vinculada, como já citado, "ao aparecimento de um irmão mais jovem [e] a todas as ocorrências em que a criança toma consciência da não evidência do vínculo de amor que a liga aos seus pais por meio dos quais ela constrói sua identidade" (MIJOLLA-MELLOR, 1999, p. 20). Para Arnaud Dubois (op. cit.), de alguma forma, a entrada na profissão do cargo

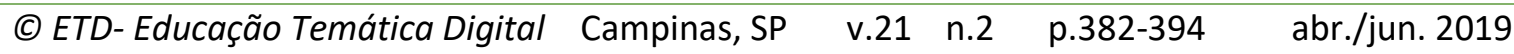


de professor reativa elementos psíquicos em relação à sua própria infância: os professores iniciantes são confrontados com a questão das origens, da mesma forma que a criança sente o nascimento de outro. Para a criança, a pergunta é: "Onde eu estava quando eu não estava lá?". Para o professor iniciante, ela surge em outras palavras, podendo ser evocada assim: "E o meu desejo de estar naquele lugar lá?".

Os professores iniciantes falam frequentemente, nos grupos de análise das práticas, sobre a desordem que experimentam frente ao comportamento de seus alunos. Essas situações parecem inacessíveis à compreensão. As situações difíceis confrontam os novos professores com a representação de não ter existido sempre como professor e não lhe ser assegurado sempre existir. Tal representação é o ponto de partida de uma necessidade de causalidade para restabelecer o sentido que entrou em colapso. O mecanismo descrito acima permite passar do desespero para a criação de um enigma na forma de uma pergunta: "De onde vem este aluno perturbador?".

Assim, Arnaud Dubois formula a hipótese que, como as crianças observadas por Mijolla-Mellor, os professores iniciantes consideram que há algo fundamental, vital, que eles não sabem, um saber oculto, que thes seria "proibido". O enigma de um saber oculto atravessa em grande parte seus discursos e muitas vezes culpam os formadores em não revelar os saberes que Ihes seriam "vitais", como mostraram as pesquisas anteriormente citadas.

Para continuar a transposição das propostas de Mijolla-Mellor relativo às crianças e aos professores iniciantes, parece que estes últimos passam em seguida da constituição do enigma a tentativas de respostas. As crianças observadas por Mijolla-Mellor elaboram o que ela chama de "mitos mágicos-sexuais" (1999). À imagem dos mitos, as respostas construídas pelos professores não demandam ser comprovadas cientificamente. Eles têm em comum com estes "mitos" o quanto várias explicações podem coabitar e o quanto as respostas contrárias podem coexistir.

A relação com saberes profissionais podem ser melhor compreendida à luz destas proposições: em reação ao que os assombra como uma questão-enigma, as respostas não têm necessidade de comprovação científica. São impossíveis de serem hierarquizadas.

\section{A CONSTRUÇÃO PSÍQUICA DO “EU PROFESSOR”}

Uma equipe de pesquisa codisciplinar animada por Claude Blanchard-Laville realizou observações de um professor de escola primária desde o seu ano de formação até o seu décimo ano de trabalho. Os resultados dessa pesquisa são apresentados no livro dirigido por Philippe Chaussecourte e publicado em 2014 sob o título: Ensinar na escola primária: dez anos com um professor das escolas (no original, Enseigner à l'école primaire: Dix ans avec un professeur des écoles). Essa pesquisa longitudinal permitiu entre outros, analisar a construção

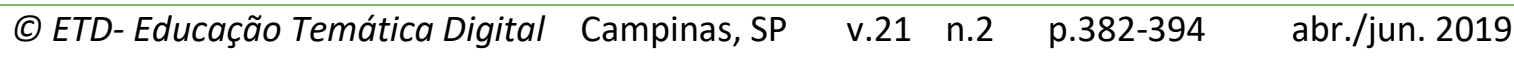


profissional no plano psíquico nos termos como Piera Aulagnier (1975) propõe concernente à construção psíquica de um sujeito.

Assim, em seu capítulo, C. Blanchard-Laville, L.-M. Bossard e C. Verdier-Gioanni (2014) propõem falar do Eu professor que seria inicialmente antecipado pelo próprio sujeito em suas representações de um eventual futuro e tomaria consistência durante a primeira situação de ensino real. Isso viria a evoluir ao longo de encontros sucessivos em um "processo contínuo de registro histórico" (AULAGNIER, 1975). Essa concepção permite entender que esse tempo de construção psíquica seja demorado, processual e marcado por micromudanças muito importantes. O nosso acompanhamento do trabalho do professor Benoît durante 10 anos após sua formação nos mostrou como, no decorrer das entrevistas, ele se situa na démarche que poderia ser qualificada como auto-historização do seu "Eu professor" (esse trabalho de historiador que nos retorna para pensarmos em nós mesmos). E também mostra como foi edificado seu projeto identificador no plano profissional para assegurar o sentimento de uma continuidade identitária, uma espécie de compromisso entre ser o efeito de uma história que nos precedeu e ser o autor de uma história que nos conta. O acompanhamento de Benoît mostrou que sua assinatura, sua maneira singular de manter sua posição de professor no plano psíquico perante os saberes e os alunos, permaneceu estável durante os 10 anos de observação, mas, em contrapartida, esse docente conseguiu fazer alguns ajustes no sentido de uma melhor correspondência para a sua posição de professor.

Assim, parece-nos que a abordagem clínica de orientação psicanalítica se propõe na maioria das vezes trabalhar na formação inicial, em acompanhar os futuros professores para iniciar a construção de sua identidade profissional, elaborando os prós e os contras desse tempo de passagem que constitui o tempo de formação. Depois, na formação contínua, se busca essa construção do seu "Eu professor" por meio da análise de situações profissionais encontradas.

Temos a hipótese de que a presença da equipe da pesquisa, além dos encontros efetivos, pode constituir, em um processo de construção identitária, um "envelope" por sua vez contendor e apoiador. Nesse sentido, e com base nessa experiência, nos parece útil refletir sobre uma forma de apoio aos professores nos primeiros anos do seu exercício. Tratase de imaginar um dispositivo muito mais leve do que este sobre o qual a pesquisa foi construída, mas que poderia, todavia, permitir-lhes ter certo recuo em relação ao que eles vivenciam todos os dias, o que facilitaria a construção de seu "Eu professor".

\section{ACOMPANHAMENTO CLÍNICO PARA A ANÁLISE DAS PRÁtICAS PROFISSIONAIS}

Em resumo, a crise de identidade de entrada na profissão se reflete pela formulação de uma queixa que na maioria das vezes se traduz em críticas dirigidas à formação e aos formadores. Nossa abordagem mostra que essa crise é estrutural, pois está relacionada com

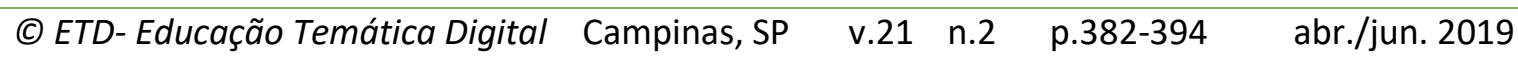


as necessárias mudanças psíquicas impostas pela função. Isso induz a um professor iniciante correr riscos, pois nenhuma formação, nenhum saber antecipado pode premuni-lo. Assim, nossa forma de conceber esse início induz a nem sempre procurar respostas em termos de melhorias ou modificações da formação. Ela implica na ideia de que logo do exercício de funções seja acompanhado e que apenas elaborações no só-depois (après-coup) as dificuldades encontradas nestes primeiros anos de exercício da profissão podem ter alguma chance de ajudar os iniciantes a atravessá-los no sentido de uma profissionalização de sua posição (BLANCHARD-LAVILLE, 2005).

Para o professor Benoît, a equipe de pesquisa certamente ajudou o seu desenvolvimento profissional, beneficiando do envelope de contenção e de apoio. Essa experiência não pode ser reproduzida em grande escala, mas inspira a ideia de que nos grupos de análise clínica das práticas profissionais, oferecidas aos professores no início da função, se poderia focar em sustentar o processo da construção de identidade, elaborando os incidentes de percurso que não podem deixar de ocorrer e as turbulências ocorridas no período de crise. Práticas clínicas inspiradas por essas pesquisas são numerosas e variadas como demonstra particularmente o livro coletivo dirigido por Giust-Ollivier e Walid (2015).

Estes grupos de análise de práticas profissionais parecem ser capazes de apoiar os processos envolvidos no início da carreira dos professores iniciantes. O objetivo é estabelecer uma conversa em pequenos grupos, focado nas implicações psíquicas da prática profissional. Antes de se juntar ao grupo, os participantes são prevenidos sobre a direção futura do trabalho proposto. Eles sabem que será privilegiada uma abordagem a partir da história pessoal e dos sentimentos internos de cada um/a. O consentimento para aderir a esse tipo de trabalho é, obviamente, importante, mesmo que isso leve algum tempo de experiência para que os participantes possam apreciar os contornos com detalhes.

A partir dos relatos - orais ou escritos - realizados pelos participantes do grupo de eventos que ocorreram no seu trabalho diário, uma exploração se desenvolve à medida dos encontros. A regularidade das sessões é necessária como um trabalho de longo prazo. Cada sessão dura de duas a três horas, dependendo das circunstâncias contextuais do estabelecimento no dispositivo. Os participantes se sentem rapidamente envolvido um com o outro. Assim, cada um/a se sente, de alguma forma, obrigado, ao seu tempo e ao seu próprio ritmo, trazer o material de sua própria prática.

Nesse tipo de espaço de acompanhamento clínico das práticas, trata-se de estabelecer um trabalho psíquico com foco na profissionalização. Esse trabalho visa facilitar notadamente o desenvolvimento da função de contenção dos participantes permitindo adquirir subjetivamente as capacidades para apoiar a sua própria postura profissional e integrar a noção do quadro clínico de trabalho. Seu objetivo é identificar os contornos da relação profissional para liberar tanto quanto possíveis os vínculos imaginários em que podem se perder; identificar os impedimentos que impedem o funcionamento como cada um o deseja

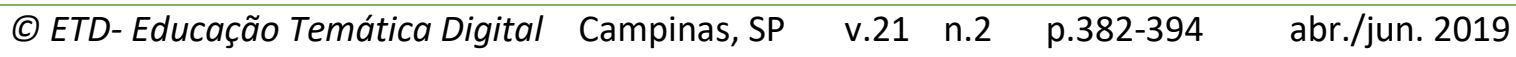


idealmente; e tentar se liberar um pouco dos obstáculos, cuja fonte não escapa no cotidiano. Trata-se de um trabalho de elaboração psíquico para promover os processos de subjetivação profissional.

Quando o quadro de trabalho opera, os participantes descobrem rapidamente os laços entre os seus modos de funcionamento e alguns cenários pessoais que determinam em parte, sem que o saiba, o jeito de funcionar em uma situação profissional. Isso pode dar-lhes um alívio importante, às vezes, uma espécie de liberação emocional, e, de todas as formas, um apoio narcísico no compartilhamento com os outros participantes, graças ao espírito de cooperação e "não julgamento" que é requerido no grupo. Cada um/a se sente menos sozinho ao ouvir o relato dos outros e, gradualmente, é possível ir além dos sentimentos de incompetência que muitas vezes nos esmagam no exercício desses trabalhos. Em nossa opinião, estimamos que o trabalho exposto psiquicamente àquele que o exerce, que é congruente com o fato do quanto se torna possível compartilhar sem muito receio das dificuldades que enfrenta, leva o sujeito a menos sofrimento no trabalho.

Em geral, cada um/a no grupo é capaz de constatar a liberação que se produz para a pessoa que a expõe, muitas vezes, até fisicamente, como se algo se tivesse desfeito, como se algo relativo ao medo tenha se dissipado. Mesmo nos casos em que a situação presente não se modificou, ocorreu certa transformação da relação da pessoa com essa situação, de sua relação consigo mesmo e com outros parceiros envolvidos na situação.

A partir do trabalho realizado nesses grupos, cada participante pôde desenvolver novas habilidades para evitar ser destruído por possíveis ataques contra seu sentimento de competência ou para o conter suficientemente, transformando-os de modo que a situação se torne novamente suportável, evitando assim a ruptura do vínculo para a passagem do ato de ambos os lados. O trabalho psíquico efetuado serve para alterar os conteúdos psíquicos relacionados às situações profissionais elaboradas. O desenvolvimento da nossa função contendora não é realizado apenas por meio de uma transmissão intelectual de saberes teóricos durante a formação. Isso requer uma experiência pessoal que permite uma reformulação psíquica e esse trabalho só pode ser realizado no a posteriori (après-coup) que as situações ocorreram. Não se trata de se desdobrar de alguma forma para poder se olhar a agir, mas, mantendo-se totalmente implicado, esse costume de trabalho no só-depois gradualmente nos torna mais sensível ao que está acontecendo e um pouco mais consciente disso que acontece e quando isso acontece.

\section{UM ESPAÇO DE TRANSICIONALIZAÇÃO DA EXPERIÊNCIA PROFISSIONAL}

De fato, o trabalho consiste menos em se preocupar com o aspecto fatual ou anedóticos das cenas evocadas e solicitadas pela situação profissional analisada do que acolher, conter e, sobretudo, transformar os afetos que estão vinculados. $O$ animador (animateur-rice) coloca-se então como mediador (médiateur-rice) da elaboração

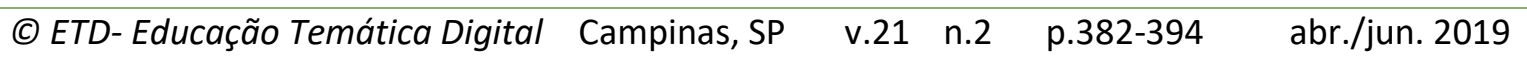


intrapsíquica para o participante que a expôs. Nesta concepção do trabalho psíquico, sustentado pelas contribuições de Bion as quais seguimos, a emoção e o afeto têm um lugar importante. Como formula René Roussillon (2013), os afetos são atores da vida psíquica, instruindo-nos sobre o que está acontecendo dentro de nós. Portanto várias configurações podem ocorrer no nível dos afetos que podem ter sido ou reprimidos ou recalcados, ou ainda ter seus laços com as representações cortados. $O$ espaço intermediário do grupo ajuda a domar esses afetos quando reaparecem de forma tão transbordante para que possam recuperar a sua função de simples sinal autoinformativo. Essas regulações, esses ajustes se efetuam por meio do psiquismo da animadora e do ambiente que constitui o conjunto dos psiquismos do grupo quando se aprendeu a trabalhar desta forma. É dentro dessa experiência intersubjetiva do compartilhamento dos afetos, que pode ser possível transicionalizar a experiência profissional, em particular transformar os afetos traumáticos.

Esse quadro grupal procura ser criador de um espaço "potencial", no sentido de Winnicott, para favorecer os processos de apropriação subjetiva e de integração de novas experiências. Hoje, estamos convencidos da "eficiência" desse enquadramento clínico grupal (cadrage clinique groupal), e de sua potência que se traduz em possibilidades de elaboração psíquica, no nível individual e grupal, resultando em melhor capacidade de pensar para os participantes. Estes efeitos são, em parte, devido a uma sinergia de recursos empáticos de todos/as participantes, ao mesmo tempo em que são a consequência do fato de que os processos psíquicos são favorecidos por essa conduta grupal e assim, concomitantemente, as forças de desenlace são temporariamente reduzidas. A postura do animador e instaurador do quadro resultante é capaz de produzir um efeito de segurança psíquica propícia para que cada um possa no grupo dispor de seu aparelho de pensar, que se trate potencializá-lo da melhor forma ou reconquistá-lo.

Em resumo, para desenvolver os processos de subjetivação profissional, o espaço de análise clínica de práticas profissionais se constitui em espaço de transicionalização da experiência profissional cotidiana, um espaço grupal em que as emoções podem ser metabolizadas, as relações com os alunos confiadas, permitindo, assim, sair do sentimento de solidão, sem cair na confusão dos lugares e onde principalmente todos podem desenvolver a sua capacidade de pensar além dos riscos de sideração, reiniciando os dispositivos de pensamento em um ambiente seguro em que ocorre uma forma de transmissão do gesto profissional (BLANCHARD-LAVILLE, 2013; 2017).

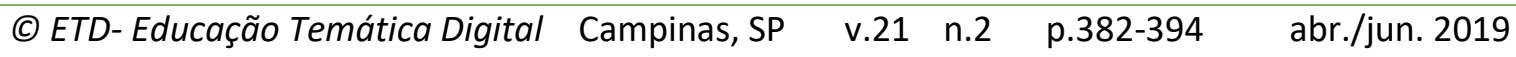




\section{REFERÊNCIAS}

AULAGNIER, Piera. La violence de l'interprétation. Paris: Puf, 1975.

BLANCHARD-LAVILLE, Claudine. Au risque d'enseigner. Paris: Puf, 2013.

BLANCHARD-LAVILLE, Claudine. Em defesa de uma clínica de orientação psicanalítica em ciências da educação. Estilos da Clínica. Instituto de Psicologia. Universidade de São Paulo: 2007. v. 12, 22, 208-223. Disponível em: http://www.revistas.usp.br/estic/article/download/46026/49651

BLANCHARD-LAVILLE, Claudine. L'analyse des besoins en formation continue des enseignants de mathématiques de l'Académie de Versailles. Rapport d'une étude commanditée par le Ministère de l'Éducation nationale et la Mission Académique de Formation des Personnels de l'Éducation Nationale de Versailles. 1995.

BLANCHARD-LAVILLE, C., BOSSARD, Louis-Marie et VERDIER-GIOANNI, Catherine. L'évolution du je enseignant de Benoît : entre " permanence et changement ». Dans $P$. Chaussecourte (Dir.). Enseigner à l'école primaire. Dix ans avec un professeur des écoles Paris: L'Harmattan, 2014. p.111-144.

BLANCHARD-LAVILLE, Claudine et NADOT, Suzanne (Dir.). Malaise dans la formation des enseignants. Paris: L'Harmattan, 2000.

BLANCHARD-LAVILLE, Claudine. Por um acompanhamento clínico coletivo do ofício de ensinar. Em aberto: (à paraître) 2017. Disponível em: www.emaberto.inep.gov.br.

BLANCHARD-LAVILLE, Claudine. Os professores, entre o prazer et o sofrimento. São Paulo: Loyola, 2005. 326 p.

BLANCHARD-LAVILLE, Claudine et NADOT, Suzanne (Dir.). Rapport intitulé «Recherche sur la formation des enseignants par le biais du suivi de cohortes». Recherche soutenue par les IUFM de Bretagne et de Versailles. 2000.

BOSSARD, Louis-Marie. La crise identitaire. Dans C. Blanchard-Laville et S. Nadot (Dir.). Malaise dans la formation des enseignants. Paris: L'Harmattan, 2000. p.97-146.

BOSSARD, Louis-Marie. Enseignants débutants: de l' " adolescence professionnelle » à la «post- adolescence professionnelle». Cliopsy, v. 2, p. 65-77. 2009.

BOSSARD, Louis-Marie. Soizic: une « adolescence professionnelle » interminable? Connexions, v.75, p. 69-83, 2001.

CHAUSSECOURTE, Philippe (Ed.). Enseigner à l'école primaire. Dix ans avec un professeur des écoles. Paris: L'Harmattan, 2014.

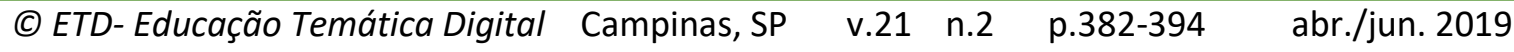


DUBOIS, Arnaud. Le " groupe monographique»: un dispositif de formation pour enseignants débutants. Cliopsy, v.13, p.77-93. 2015.

FREUD, Sigmund. Sur les théories sexuelles infantiles. Oeuvre complète de Freud, v. VIII, Paris: PUF, 1908 [2007].

GIUST-OLLIVIER, Annie-Charlotte et OUALID, Florence (Dir.). Les groupes d'analyse des ratiques. Toulouse: Érès, 2015.

GUIGNARD, Marc. Devenir enseignant de mathématiques: étude des modalités du transfert didactique. Vers une prise en compte d'une parentalité psychique interne. Thèse Université Paris-Descartes. 30 juin. 2017.

JACOBI, Benjamin. Les mots et la plainte. Toulouse: ÉRÈS, 1998.

JACOBI, Benjamin. Plainte et adolescence, Adolescence, 17, 133-143. 1999.

MIJOLLA-MELLOR, Sophie de. Les mythes magico-sexuels sur l'origine et sur la fin. Topique, v.68, p.19-32. 1999.

MOSCONI, Nicole. Les enjeux psychologiques de la prise de fonction des enseignants. La prise de fonction des personnels de l'éducation, Actes du Vlème colloque de L'AIRPE. Sèvres: Centre International d'Études Pédagogiques, 1990.

MOTTEAU, Daniel. Étude d'un entretien de professeur des lycées et collèges stagiaire. Malaise et plainte dans le discours. Dans C. Blanchard-Laville et S. Nadot (Dir.). Rapport intitulé «Recherche sur la formation des enseignants par le biais du suivi de cohortes». Recherche soutenue par les IUFM de Bretagne et de Versailles, 2001.

ROUSSILLON, René. Paradoxes et situations limites de la psychanalyse. Paris: Puf, 2013. SIBONY, Daniel. Entre-deux. L'origine en partage. Paris: Seuil, 1997.

TRIANDAFILLIDIS, Alexandra. Stratégies d'immortalité. Adolescence, v.72, n.2, p. 443-460. 2010.

Revisão gramatical realizada por:

André Luís de Souza Lima

E-mail: andrelslima82@gmail.com 